\title{
APPENDIX A: SIMPLE STEP-BY-STEP GENERIC PROCUREMENT MANUAL
}

\section{SECTION 1: PREPARATION OF A PROCUREMENT PLAN}

\section{Steps}

Thoroughly study the project, its objectives and its organization into components, sub-components and activities to achieve those objectives. A carefully designed and prepared project would already include information about the goods, works, and services that would be needed to achieve its objectives. Ensure that the project is fully funded and funds for procurement of goods, works, and services will be available before procurement actions are initiated or tender notices are issued. Procurement plan ensures that project needs in terms of goods, works, and services are met in a timely and costefficient manner in accordance with the overall project implementation schedule.

Work with the project team to elaborate a detailed and realistic procurement plan for the whole life of the project. A project team is responsible for implementing the project and 
generally includes a project manager, technical experts, procurement specialists, financial management specialists, accountants, monitoring and evaluation specialist, etc. in elaborating a realistic procurement plan.

With the help of the technical members of the team, begin by listing all the items of goods, works, and services needed for the project. For example, for an education project including construction of new schools, rehabilitation of old ones, provision of computer and laboratory equipment, furniture, textbooks, training of teachers, it would be easy to list computers, laboratory equipment, textbooks, etc., for works only the number of schools to be built and rehabilitated can be included in the list. For these works, there will be need of engaging the services of architects (firm or individual) to elaborate all the details. Engaging the services of architect will then become consultancy assignments. Teacher training will also be categorized as consultancy services as a teacher training entity will have to be hired to train teachers.

Once a list of items of goods, works, and services, as discussed in step above, has been prepared, each of these will be costed to estimate the cost of each contract package for goods, works, and each consultant assignment. Correctly estimating the cost of a contract package is a key to successful project implementation. Cost over or under runs result from incorrect cost estimates. There are many resources available for cost estimating. These, among others, are existing information that the buyer has from other similar projects and contracts, cost data bases that some government maintain, catalogues on internet, websites of relevant firms, etc.

Once the costing of the items has been completed, the next step in procurement planning is to prepare contract packages. This is necessary for economic and efficient procurement. In contract packaging, similar items of goods, works, and services are combined in discreet bundles for procurement 
purposes. However, this bundling has to be done in light of the overall project implementation schedule. In other words, not all the schools in an education project can be built in the first year of the project or left to the last year. The cost of each item in a contract package added together becomes the estimated cost of that package and is used to determine the procurement method to be used.

Once contract packages and their estimates costs have been prepared, an appropriate method is selected from the menu of procurement methods stipulated in the public procurement law/act or regulation, such as open tendering, limited bidding, shopping, or direct contracting. Determination of a procurement method will depend on the applicable monetary thresholds that governments establish by laws or decrees.

The next step in procurement planning is determining the date of delivery of the pieces of equipment included in a contract, completion of construction or rehabilitation of a building, or completion of a consultancy assignment. This date of delivery or completion date is collaboratively derived by the project team from the overall project implementation schedule. The milestones of the procurement of a contract package (preparation of tender documents, advertisement, bid preparation time, bid submission and opening, bid evaluation and contract award and signature) are calculated backward from the date of delivery or completion. Sometimes the date of delivery or completion does not allow enough time for properly applying a procurement method. In such cases, the date of completion has to be modified to allow enough time for procurement to be conducted economically and efficiently.

In order to attain the milestones included in the procurement plan, it is important that a separate plan be prepared for preparation of technical specifications for each contract package of goods and works, and terms of reference of 
consultant assignments. Frequently, procurement plans fail (or at least need too many adjustments) because of delays in finalization of technical specifications and terms of reference. Therefore, before a procurement plan is prepared, a plan for preparation of technical specifications and terms of reference should be elaborated and implemented.

Review and update procurement plans when needed but at least every six months.

\section{SECTION 2: UNIVERSAL PROCUREMENT METHODS}

\section{Goods and Work}

Open Tendering/Bidding

Steps to be followed:

1. Ensure that funds are available for the contract package being procured.

2. Prepare a detailed processing schedule for the contract package, including preparation of technical specifications, bidding documents, advertisement, submission of bids, opening of bids, evaluation of bids and contract award.

3. Prepare technical specifications.

4. Verify that the contract package to be procured is included in the approved annual procurement plan.

5. Prepare draft bidding documents.

6. Prepare tender notice and publish it.

7. Send bidding documents to interested bidders. 
8. Receive bids by a deadline, open them, and evaluate them.

9. Prepare an evaluation report using the national evaluation template, if any. If not used the attached sample.

10. Approve the evaluation report and recommendation for contract award by the procurement decision committee.

11. Sign the contract.

12. Keep the process confidential until the contract has been awarded.

13. Publish contract award.

14. Receive and inspect goods and make payments as per the purchase order.

15. Keep all documents on file.

Limited or Restricted Tendering/Bidding

Steps to be followed:

1. Verify that the contract package to be procured is included in the approved annual procurement plan and that budgetary funds for the package are available.

2. Prepare a detailed processing schedule for the contract package, including preparation of technical specifications, bidding documents, list of bidders to be invited, submission of bids, opening of bids, evaluation of bids and contract award.

3. Prepare technical specifications.

4. Prepare draft bidding documents.

5. Send bidding documents to the identified bidders.

6. Receive bids by a deadline, open them, and evaluate them. 
7. Prepare an evaluation report using the national evaluation template, if any. If not used the attached sample.

8. Approve the evaluation report and recommendation for contract award by the procurement decision committee.

9. Sign the contract.

10. Keep the process confidential until the contract has been awarded.

11. Publish contract award.

12. Receive and inspect goods and make payments as per the purchase order.

13. Keep all documents on file.

\section{Request for Quotations or Shopping}

Steps to be followed:

1. Ensure that the contract package for goods or works to be prepared are included in the annual approved procurement plan, and that the budgetary funds for the package are available.

2. Prepare technical specifications.

3. Prepare list of suppliers or contractors broad enough to generate good competition and to yield at least three quotations, as required. Such a list may be prepared based on the past experience, consultation with chambers of commerce, Internet, or direct market research.

4. Prepare invitation to quote (ITQ) using existing national templates. If templates not available, use samples.

5. Send the ITQ to the suppliers and contractors. 
6. Make sure that the requirement of obtaining a minimum of three quotations has been fulfilled.

7. Receive quotations by a deadline, open them, and evaluate them.

8. Prepare an evaluation report using the existing national template; if a template does not exist, use the attached sample.

9. Get approval of procurement decision committee as required.

10. Sign the contract.

11. Keep the process confidential until the contract has been awarded.

12. Publish contract award information (the name of the selected supplier/contractor, the contract price) in a national newspaper.

13. Receive and inspect goods and make payments as per the purchase order.

14. Keep all documents on file.

Direct Contracting for Goods and Works

Steps to be followed:

1. Verify that the approved procurement plan includes the goods and works to be procured, and that budgetary funds for the package are available.

2. In case of emergency procurement, follow Steps 3-5; otherwise proceed to Step 6.

3. Prepare estimated cost of the goods or works to be procured directly from a single course. 
4. For preparation of cost estimates for direct contracting, obtain market prices of the required goods/works; and information about prices being charged by the supplier/ contractor to other customers.

5. Prepare justification for direct contracting.

6. Seek and obtain approval of the competent authority for the proposed direct contracting.

7. Prepare technical specifications and contract conditions.

8. Prepare and send letter of invitation, including contract conditions, required delivery/completion time, technical specifications, deadline for submission of bid.

9. Receive and evaluate bid.

10. Make sure that the prices being charged are at least the same as the supplier charges to its other customers; Also, prices should be comparable to the prevailing prices of the relevant goods/works.

11. Keep the process confidential.

12. Publish information about contract award.

13. Sign the contract.

14. Keep all documents on file.

\section{Consultant Services}

Quality and Cost Based Selection (QCBS)

Steps to be followed:

1. Verify that the contract package for the required consultant services is included in the procurement plan, and that the funds are available for this contract package. 
2. Prepare a detailed processing schedule for the contract package. Use national templates, if any; if not, use the sample attached.

3. Publish notice for expression of interest for preparing a shortlist of firms to be invited to submit a technical and financial proposal. For this purpose, use national template, if any; if not, use the sample attached.

4. Prepare request for proposal (RFP) using the national template.

5. Receive and evaluate expressions of interest by the deadline (usually two weeks from the date of the publication of the notice) from interested firms. Use relevant experience of the firm, its staffing, and financial status as the evaluation criteria. Based on these factors, elaborate and use an point-based evaluation system.

6. Prepare evaluation report and include in it, along with all the details, a ranked list of all the firms which expressed interest. The evaluation report should also include the evaluation committee's recommendation, which should be in conformity with the national public procurement laws and regulations, for shortlisting the firms. IFIs usually allow six top ranking firms to be shortlisted but the national legislature in this regard varies from country to country. Any shortlist of firms to be invited must be in conformity with the prevailing public procurement act and regulations.

7. Send the RFP (Step 4) to the shortlisted firms.

8. Receive technical and evaluation proposals by the deadline (usually 30 days from the date of issue of the RFP); open the technical proposals and prepare minutes. 
9. Evaluate them using a point system of evaluation and establish a ranking of the interested firms. Prepare an evaluation report and seek and obtain the approval of the competent authority for the shortlist included in the evaluation report. Do not open the envelopes containing the financial proposal. The receipt of envelopes should always be recorded by someone other than the official who prepared the RFP. Keep them intact in a safe place where they are not accessible to personnel other than those who need to have access to them.

10. Evaluate the technical proposal in accordance with the point-based evaluation criteria included in the RFP; prepare an evaluation report including a ranking of the firms according to the points received by their technical proposals; submit the evaluation report to the competent authority for approval before proceeding with the opening of the financial proposals of the firms which scored the minimum or above for their technical proposals.

11. Invite the qualified firms to the public opening of the envelopes containing their financial proposals. Allow them sufficient time to prepare themselves to participate in the public opening.

12. In the public opening, announce the technical scores obtained by each firm, open the envelopes containing the financial proposals one by one and announce the price included in each proposal. Prepare minutes of public bid opening and forward these to all who submitted a proposal.

13. Evaluate the financial proposals by allocating weight to the price of each firm as stipulated in the RFP. Combine the technical and financial scores. 
14. Prepare an evaluation report using the existing template; if a national template does not exist, use the sample.

15. Submit the evaluation report to the competent authority for approval before inviting the selected firm for contract negotiations.

16. Contract negotiations are usually held at the premises of the client and begin with the review and finalization of the terms of reference.

17. Prepare contract negotiations.

18. After the result of the contract negotiations has been approved by the competent authority, both parties should sign the contract.

19. All the papers relating to the process should be kept on file.

20. Ensure that consultant is performing according to the contract terms and condition.

\section{Quality Based Selection (QBS)}

Steps to be followed:

1. Verify that the contract package for the required consultant services is included in the procurement plan and budgetary funds are available for this package.

2. Prepare a detailed processing schedule for the contract package. Use national templates, if any; if not, use the sample attached.

3. Publish notice for expression of interest for preparing a shortlist of firms to be invited to submit a technical and financial proposal. For this purpose, use national template, if any; if not, use the sample attached. 
4. Prepare RFP using the national template.

5. Receive and evaluate expressions of interest by the deadline (usually two weeks from the date of the publication of the notice) from interested firms. Use relevant experience of the firm, its staffing, and financial status as the evaluation criteria. Based on these factors, elaborate and use an point-based evaluation system.

6. Prepare evaluation report and include in it, along with all the details, a ranked list of all the firms which expressed interest. The evaluation report should also include the evaluation committee's recommendation, which should be in conformity with the national public procurement laws and regulations, for shortlisting the firms. IFIs usually allow six top ranking firms to be shortlisted but the national legislature in this regard varies from country to country. Any shortlist of firms to be invited must be in conformity with the prevailing public procurement act and regulations.

7. Send the RFP (Step 4) to the shortlisted firms.

8. Receive technical and evaluation proposals by the deadline (usually 30 days from the date of issue of the RFP); open the technical proposals and prepare minutes.

9. Evaluate them using a point system of evaluation and establish a ranking of the interested firms. Prepare an evaluation report and seek and obtain the approval of the competent authority for the shortlist included in the evaluation report. Do not open the envelopes containing the financial proposal. Keep them intact in a safe place where they are not accessible to personnel other than those who need to have access to them. 
10. Evaluate the technical proposal in accordance with the point-based evaluation criteria included in the RFP (note that in case of QBS $100 \%$ of the weight is allocated to quality); prepare an evaluation report including a ranking of the firms according to the points received by their technical proposals; submit the evaluation report to the competent authority for approval before proceeding with the opening of the financial proposals of the firm which scored the highest mark for its technical proposal.

11. Invite the highest ranking firm for contract negotiations.

12. Contract negotiations are usually held at the premises of the client and begin with the review and finalization of the terms of reference.

13. Prepare contract negotiations.

14. After the result of the contract negotiations has been approved by the competent authority, both parties should sign the contract.

15. All the papers relating to the process should be kept on file.

16. Ensure that consultant is performing according to the contract terms and condition.

Least Cost Selection (LCS)

Steps:

1. Verify that the contract package for the required consultant services is included in the procurement plan and ensure that the budget funds for this contract package are available. 
2. Prepare a detailed processing schedule for the contract package. Use national templates, if any; if not, use the sample attached.

3. Publish notice for expression of interest for preparing a shortlist of firms to be invited to submit a technical and financial proposal. For this purpose, use national template, if any; if not, use the sample attached.

4. Prepare RFP using the national template.

5. Receive and evaluate expressions of interest by the deadline (usually two weeks from the date of the publication of the notice) from interested firms. Use relevant experience of the firm, its staffing, and financial status as the evaluation criteria. Based on these factors, elaborate and use an point-based evaluation system.

6. Prepare evaluation report and include in it, along with all the details, a ranked list of all the firms which expressed interest. The evaluation report should also include the evaluation committee's recommendation, which should be in conformity with the national public procurement laws and regulations, for shortlisting the firms.

International Financial Institutions (IFIs) usually allow six top ranking firms to be shortlisted but the national legislature in this regard varies from country to country. Any shortlist of firms to be invited must be in conformity with the prevailing public procurement act and regulations.

7. Send the RFP (Step 4) to the shortlisted firms.

8. Receive technical and evaluation proposals by the deadline (usually 30 days from the date of issue of the RFP); open the technical proposals and prepare minutes. 
9. Evaluate them using a point system of evaluation and establish a ranking of the interested firms. Prepare an evaluation report and seek and obtain the approval of the competent authority for the shortlist included in the evaluation report. Do not open the envelopes containing the financial proposal. Keep them intact in a safe place where they are not accessible to personnel other than those who need to have access to them.

10. Evaluate the technical proposal in accordance with the point-based evaluation criteria included in the RFP (note that $100 \%$ of the weight in LCS is allocated to technical quality of the proposal); prepare an evaluation report including a ranking of the firms according to the points received by their technical proposals; submit the evaluation report to the competent authority for approval before proceeding with the opening of the financial proposals of the firms which scored the minimum or above for their technical proposals.

11. Invite the qualified firms to the public opening of the envelopes containing their financial proposals. Allow them sufficient time to prepare themselves to participate in the public opening.

12. In the public opening, announce the technical scores obtained by each firm, open the envelopes containing the financial proposals one by one, and announce the price included in each proposal. Prepare minutes of public bid opening and forward these to all who submitted a proposal.

13. Invite the firm with the least price among the ones whose technical proposals scored above the minimum for negotiations. 
14. Contract negotiations are usually held at the premises of the client and begin with the review and finalization of the terms of reference.

15. Prepare contract negotiations;

16. After the result of the contract negotiations has been approved by the competent authority, both parties should sign the contract.

17. All the papers relating to the process should be kept on file.

18. Ensure that consultant is performing according to the contract terms and conditions.

Single (Or Sole) Source Selection (SSS)

Steps:

1. Verify that the contract package for the required consultant services is included in the procurement plan and ensure that the budget funds are available for procuring the required needs.

2. If not already done, formally justify sole sourcing and seek the necessary approval before proceeding with the selection process. In order to justify sole sourcing, generally three conditions must exist: (i) natural continuation of services already performed or being performed;

(ii) declared and recognized natural disasters and emergencies; and (iii) the assignment requires exceptional skills and experience.

3. Prepare terms of reference and, if not already done as part of the procurement plan, estimate the cost of the assignment. In sole sourcing, which is procurement of services 
without any competition, the use of the cost estimate as a reference point is essential. This is to avoid the consultant being invited on a single source basis charging the client excessive prices, if not more than market prices. For estimating the cost of the assignment, use recent past or existing contracts, other clients, and information about prices available on internet.

4. The invitation package to be sent to the consultant intended to be invited should include a letter of invitation, terms of reference, and contract conditions. The objective of the invitation package is to provide the consultant with all the necessary information about the assignment to help him prepare its proposal (both technical and price), and submit it to the client by a prescribed deadline.

5. Study the technical proposal carefully to ensure that it is responsive to the requirements as set out in the terms of reference. Carry out a cost analysis of the proposal to ensure that the prices charged are comparable to the prevailing market prices. If necessary, negotiate contract conditions and unit prices with the consultant. Record minutes of negotiations and sign the contract.

6. Monitor consultant performance regularly to ensure that the consultant adheres to the schedules included in the contract. Put the consultant on notice for any delays in contract performance. When consultant submits a draft report, review it promptly, and provide comments as needed. This is important because in consultant contracts submission of draft reports serve as triggers for payment. 


\section{SECTION 3: EVALUATION OF BIDS AND CONSULTANT PROPOSALS \\ Evaluation of Bids for Goods, Works, and Technical Services}

\section{Steps}

After the public opening of bids, the bids received and the bidding documents and other related documents are distributed to the bid evaluation committee. The bid evaluation committee usually comprises three to five members, including one or two members with technical skills in the goods or works being procured. For example, if X-ray machines are being procured, one or two members of the team must have technical skills relating to X-ray machines.

The evaluation committee members strictly follow the evaluation criteria as disclosed in the bidding documents. First, they carry out a preliminary examination of the bids to ensure that the bids received substantially meet all the requirements (legal, commercial, and technical) as stated in the bidding documents. Bids with major deviations are rejected at this stage and considered no further. Bids that are responsive to the requirements, even with minor deviations, move to the next stage of evaluation, which is price comparison. At this stage qualification of bidders are not considered. See Step 4 below.

At this stage, the prices of the responsive bids are compared and adjustments for deviations made according to the parameters included in the bidding documents for this purpose. The adjustments at this stage are made only to make the bids with deviations fully comparable to the responsive bids so that their prices are being compared on an equal basis. The main objective of the comparison of bid prices, including adjusted bid prices, is to rank all the responsive 
bids, e.g., lowest evaluated responsive bid, second lowest evaluated responsive bid, and so on. The lowest evaluated responsive bid then passes to the next and final stage of bid evaluation before contract award. It is called postqualification, in case a PQ exercise has not been conducted.

The main objective of the post-qualification $(\mathrm{PQ})$ exercise is to ensure that before a contract is awarded the lowest evaluated responsive bidder (or the selected/winning bidder) has the necessary qualification, experience, personnel, machinery, and financial capacity to perform the contract. For this purpose, the bidding documents include clear PQ requirements against which the selected bidder's qualifications are checked and if the bid passes the test, it moves to the next stage of evaluation, i.e., contract award notification; if not, the bid is rejected, and the second lowest evaluated bid is postqualified.

The evaluation process and its outcome are recorded in detail in an evaluation report. The evaluation report must show that evaluation of each bid has been carried out in keeping with the evaluation criteria in the bidding documents, and no external factors have been taken into account. Evaluation report also records information and justification about rejection of any bid.

\section{Evaluation of Consultant Proposals}

\section{Steps}

In case of QCB, QCBS, fixed budget (FB), and LCS, the consultant proposals are received in two separate closed envelopes, one containing the technical proposal and the other the price proposal. The main purpose of this procedure is to ensure that evaluators are not biased by consultants' proposed prices and first consider only the technical merits of 
their proposal. Therefore, in these selection procedures, first the envelopes containing the technical proposals are opened, and only after the technical proposals have been evaluated, the envelopes containing the price proposals are opened in public in order to ensure transparency of the process. Until the price envelopes are opened, they are kept closed in a secure place or with a third party.

A point system of evaluation is used for selecting consultants, as follows:

1. In QCB, $100 \%$ of the weight is allocated to technical quality of the proposal and price proposal is negotiated with the highest ranking firm.

2. In QCBS, depending on the nature of the assignment, generally $75 \%$ of the weight is allocated to technical quality and up to $25 \%$ to price, and the contract is negotiated with the highest ranking firm.

3. In $\mathrm{FB} 100 \%$ of the weight is given to technical quality; and the contract is negotiated with the highest ranking firm with the price at or below the declared budget.

4. In LCS, $100 \%$ of the weight is allocated to technical quality; and the contract is negotiated with the highest ranking firm with the lowest price.

Generally, the following factors are used for evaluation, although additional factors and sub-factors can be added and the points sub-divided further:

- Specific experience of consultant - 0-10 points.

- Methodology to carry out the assignment - 20-50.

- Key personnel - 30-60. 
In each selection method above, the technical proposal of a consultant must obtain 75 points or above to be considered further. Any proposal that fails to obtain at least 75 points is rejected. This requirement is called quality threshold. Any technical proposal not meeting this requirement is considered to be of unacceptable quality.

The technical proposals and RFPs are distributed to the evaluation committee which comprises three to five members with specialization in the subject of the assignment for which the consultant is being selected. Each member of the evaluation committee studies each technical proposal carefully and allocates points based on the content of the proposal and in accordance with the evaluation criteria disclosed in the RFP. The committee members meet and discuss their allocated scores and reach a consensus in case of large differences in their scores.

The evaluation committee prepares a technical evaluation report that includes the scores given by each individual evaluator; their justification through a discussion of strengths and weaknesses of each proposal; and their aggregation. The firms obtaining at or above the quality threshold are formally invited to participate in public opening of the envelopes containing their price proposals.

The envelopes containing the price proposals are opened by the designated procurement committee in the presence of the representatives of the participating consultants. The committee opens each envelope and announces the price proposed plus the score obtained by the technical proposal of the consultant concerned. The committee prepares minutes of the opening of the price proposals.

In the next step, the committee evaluates the price proposals using a point system on a scale of $0-100$. Usually, the committee uses a formula in which highest score (i.e., 100) is allocated to the lowest price and then the scores are given to 
other proposed prices in inverse proportion. As a result, the lowest price obtains the highest score and the highest price obtains the lowest score. Once the price proposals have been assigned scores, both the technical and price scores are weighted using the weights allocated in the RFP (see above).

The committee prepares full evaluation report combining technical and financial evaluation results, and the firm which obtained the highest weighted score for its technical and financial proposals is invited for contract negotiations.

\section{SECTION 4: CONTRACT MANAGEMENT}

\section{Steps}

Preferably during the procurement process or at the latest upon contract signature, the head of the agency responsible for the project should appoint a contract manager with the qualifications relevant to the subject of the contract. The contract manager should be made responsible and accountable for the timely implementation of the contract. He or she should be provided with the necessary technical, legal, accounting, and secretarial support commensurate with the needs of the contract. Depending on the size, nature, and complexity of the contract, the support may be ad hoc provided by different relevant departments or a contract management team with members providing the necessary skills mix for managing the contract. This team, led by the contract manager, should be entrusted with the responsibility of ensuring that both the parties implement the contract in accordance with the terms and conditions of the contract. Clear terms of reference should be prepared for the contract manager and each member of the contract management team. 
Effective communication among the contract management team, between the team and relevant agency departments and other government bodies, and the supplier/contractor is a key to timely and cost effective implementation of the contract. The contract manager, therefore, should, right at the beginning, establish a sound communication system and introduce the necessary rules for flow of information among different relevant stakeholders. For this purpose, the contract management team should meet the supplier/contractor and its personnel and apart from introductions should identify, discuss, and resolve any issues that might impede contract implementation. Such meetings can be cost effectively held on a regular basis using the available information technology. However, communication on legal matters should be conducted in accordance with the provisions set out in the contract. Good record keeping is also an important part of sound communication system. The contract management team should, therefore, introduce the necessary record keeping rules or enforce the existing ones.

The contract management team should ensure that the supplier/contractor has submitted the necessary performance security in the form and amount specified in the contract. It should make arrangements for verifying the authenticity of the performance security guarantee and make arrangements for its safe keeping.

The contract manager, supported as necessary by the team, should closely monitor the supplier/contractor's compliance with the contract conditions, and issue reminders as needed. He should also establish a team comprising technical experts for inspecting and testing goods upon delivery. In case of works contracts, the engineer(s) on the contract management team should continuously supervise works, measure and certify completed works including consistency of the quality and workmanship of the completed works with the 
standards specified in the contract. In case of delays, the contract management team should promptly apply the remedies, including imposition of liquidated damages, termination of contract for default, etc.

Once the goods have been delivered (works measured), inspected, and accepted, the contract manager should ask the accounting department to process the payment to the supplier, and ensure that payments to the contractor and supplier are made in a timely manner.

Throughout the contract implementation period, the contract manager should take necessary measures to ensure that contract implementation documents, including invoices, payment certificates, receipts, inspection reports, etc., are made available to internal and external auditors as requested by them.

SECTION 5: USEFUL PROCUREMENT LINKS

OECD/DAC www.oecd.org/dac

OECD/SIGMA www.oecd.org/site/sigma

UNCITRAL www.uncitral.org

EUROPEAN UNION www.europe.eu/procurement

WB

www.worldbank.org/procure

ADB www.adb/procure

AfDB www.AfDB/procure

Inter-American Bank www.IAD/procure

WTO www.wto.org/gpa

UK www.ukprocurement.com/

procurement-guidelines

US

www.whitehouse.gov/procurement 